\title{
Synthesis, characterization and antibacterial activity of novel poly(silyl ether)s based on palm and soy oils
}

\author{
Issam Ahmed Mohammed ${ }^{1 *}$, Syed Shahabuddin ${ }^{2 *}$, Rashmin Khanam ${ }^{3}$ and Rahman Saidur ${ }^{2}$ \\ 'Department of Chemistry, Faculty of Science, University of Malaya, Kuala Lumpur, Malaysia \\ ${ }^{2}$ Research Centre for Nano-Materials and Energy Technology - RCNMET, School of Science and \\ Technology, Sunway University, Selangor Darul Ehsan, Malaysia \\ ${ }^{3}$ Centre for Interdisciplinary Research in Basic Sciences, Jamia Millia Islamia, New Delhi, India \\ *issam_usm@yahoo.com orissam@um.edu.my
}

\begin{abstract}
In this research, palm oil and soy oil were used as a natural polyol to prepare novel poly(silyl ether)s. Palm oil and soy oil were first converted to monoglyceride by one step via alcoholysis process in the presence of $0.1 \% \mathrm{CaO}$ as a catalyst. The monoglycerides were characterized by Fourier transform infrared spectrometer (FT-IR), nuclear magnetic resonance (NMR) and iodine test. The novel poly(silyl ether)s were prepared via polycondensation reaction between dimethyldichlorosilane with monoglycerides based on palm and soy oils, respectively. FT-IR, NMR and silicone-29 ( ${ }^{29} \mathrm{Si}$ NMR) were used to confirm and determine the presence of silicone in the synthesized polymers. Thermal behavior was studied by thermogravimetric analysis (TGA) and differential scanning calorimetry (DSC). Antibacterial activity of the polymers was screened against three different strains of bacteria, namely Escherichia coli E266, Staphylococcus aureus S276 and Salmonella choleeraesuis 10708.
\end{abstract}

Keywords: antibacterial, dimethydichlorosilane, palm oil, poly(silyl ethers), polyol, soy oil.

\section{Introduction}

Currently, the consumption of polymeric materials such as plastics, resins, adhesives etc. has increased enormously throughout the world. Polymers and polymeric based materials have been used extensively for various applications and have become the essential part of scientific study and research ${ }^{[1,2]}$. Polymeric materials comprising of inorganic and metal elements have always been the focus of many researchers to harness the unique properties of such polymers. Poly(silyl ether)s, for instance, is a silicon containing polymer which epitomizes an important category of useful materials such as polymeric membranes ${ }^{[3]}$, conducting polymers ${ }^{[4]}$, plastics and elastomers ${ }^{[5-7]}$, stimulus-sensitive materials and so on $^{[8]}$. Silicon containing polymers, commonly known as polysiloxanes, have received much scientific consideration as a functional and high-performance polymeric materials owing to their significant flexibility at low temperatures and enhanced stability at high temperatures. Due to the presence of $\mathrm{Si}-\mathrm{O}-\mathrm{Si}$ skeleton within the polymeric matrix, polysiloxanes exhibits enhanced performance at high and low temperatures and have been used as elastomers and high performance plastics in various industrial applications ${ }^{[9]}$.

Poly(silyl ether) is a polymer containing $\mathrm{O}-\mathrm{SiR}_{2}-\mathrm{O}$ linkage in its main chain which is responsible for its unique properties such as high thermal stability, good mechanical properties, good processibility and low glass transition temperature ${ }^{[10,11]}$. Due to the non-toxicity of poly(silyl ether)s, most of these polymers find potential application in medical field such as an artificial skin to cover wounds, optical lenses and implants etc., as they are non-cytotoxic and there is no evidence of causing adverse effect on the human body. Additionally, the unique hydrolytic reactivity of poly(silyl ether)s makes them attractive in many other applications ${ }^{[12]}$. Therefore, it has been a material of immense interest in the preparation of polymers based on silicon with respect to evaluate their biological activity ${ }^{[13]}$.

Environmental pollution has been a serious issues and various researches are dedicated to lower down the menace cause by various pollutants ${ }^{[14,15]}$ including petroleum products. As it is known, most of the poly(silyl ether)s have been prepared via polycondensation reaction between dichlorodiorganosilanes with various diols which are usually derived from petroleum products ${ }^{[16-18]}$. The global warming and environmental issues have gained the interest of researchers in attempt to replace or reduce the petroleum sources by green, biodegradable and renewable sources. Vegetable oil with the major composition of triglycerides, and saturated and unsaturated fatty acids has gained significant scientific attention as natural resources for research and development works in substitution of petroleum sources as it is present abundantly and is an economic biological source ${ }^{[19,20]}$. Polyol derived from vegetable oils acts an important precursor in the polymer synthesis, and subsequently the polymerization is carried out with different raw materials to produce various types of polymers, such as alkyd-epoxy $\operatorname{resin}^{[21]}$, hydrogels ${ }^{[22]}$ polyurethanes ${ }^{[23-26]}$, polyesters ${ }^{[27,28]}$ and poly(alkyd urethane)s ${ }^{[29]}$.

However, up to date, there is no research report on the synthesis of poly(silyl ether)s based on vegetable oils and 
their bioactivities. We have reported a novel approach for the synthesis poly(silyl ether)s based on palm oil and soy oil for the first time. This article describes a one-step reaction of palm oil and soy oil with glycerol in the presence of catalyst to produce monoglycerides. These monoglycerides functions as polyols, and subsequently these polyols are reacted with dichlorodimethysilane to produce new poly(silyl ether)s. The structures, properties and antibacterial activities of the polymer were investigated and discussed.

\section{Experimental}

\subsection{Materials}

Palm and Soy oils were purchased from commercial sources, (Seri Murni Sdn.Bhd.) and (VJ AGGRO Sdn. Bhd.), respectively. Glycerol, dichlorodimethylsilane, pyridine, sodium thiosulfate, potassium iodide, dimethylformamide (DMF) and tetrahydrofuran (THF) were purchased from Aldrich-Sigma. All the chemicals were purchased and used without further purification except for pyridine which was distilled by using the standard method.

\subsection{Synthesis of monoglycerides of soy and palm oils}

Briefly, $146.5 \mathrm{~g}$ of soy oil and $0.1 \%$ calcium oxide (based on oil) were placed in the reaction flask. $15.5 \mathrm{~g}$ glycerol was filled into the dropping funnel and fitted to the reactor flask. The reaction mixture was then heated at $235^{\circ} \mathrm{C}$ under vigorous stirring. For the first 5 minutes, nitrogen gas was allowed to flow swiftly, and later adjusted to one bubble per second throughout the experiment. The dropping funnel was then opened steadily until all glycerol was poured into the flask. The reaction mixture was kept under constant stirring for 4 hours. A sample of polymer solution was taken after regular interval using glass rod to test the solubility in ethanol. The reaction was assumed to be completed until the solution obtained has negative presence of emulsion or white spots in ethanol. Similar procedure was followed for the synthesis of monoglycerides of Palm Oil where $128 \mathrm{~g}$ of palm oil was used under analogous conditions as for soy oil monoglycerides. Scheme 1 illustrates the monoglycerides preparation.

\subsection{Synthesis of poly(silyl ether)s derived from soy oil}

$70 \mathrm{~g}(0.076 \mathrm{~mol})$ of monoglyceride of soy oil was dissolved in $13.24 \mathrm{~g}$ of pyridine with continuous stirring under nitrogen atmosphere. $23.77 \mathrm{~g}$ of dichlorodimethylsilane was then transferred to a dropping funnel and added dropwise to the mixture. Then, the mixture was stirred at room temperature for 48 hours and afterwards the temperature was raised to $60^{\circ} \mathrm{C}$ for 3 hours. The reaction mixture was then poured into $50 \mathrm{ml}$ of $10 \% \mathrm{HCl}$ solution. The precipitate obtained was washed several times with methanol and acetone and dried at $60^{\circ} \mathrm{C}$ in a vacuum oven.

\subsection{Synthesis of poly(silyl ether)s derived from palm oil}

$62.14 \mathrm{~g}(0.1258 \mathrm{~mol})$ of monoglyceride of palm oil was dissolved in $12.84 \mathrm{~g}$ of pyridine with continuous stirring under nitrogen atmosphere. Then, $23.05 \mathrm{~g}$ of dichlorodimethylsilane was subsequently added dropwise to the mixture. The rest of the work-up procedure was the same as described in the previous section for soy oil. Scheme 2 illustrates the poly(silyl ether)s preparation derived from monoglycerides.

\subsection{Instrumentation}

FT-IR spectra was measured on a Perkin-Elmer 2000 FTIR with a potassium bromide $(\mathrm{KBr})$ beam splitter. All spectra were collected between $4000 \mathrm{~cm}^{-1}$ to $400 \mathrm{~cm}^{-1}$. ${ }^{1} \mathrm{H}$ NMR spectra were recorded by Bruker $500 \mathrm{MHz}$ spectrometer, and the samples for monoglycerides and polymers were prepared at the concentration of $100 \mathrm{mg} / \mathrm{ml}$ in DMSO- $\mathrm{d}_{6}$ and $\mathrm{CDCl}_{3}$ as solvents, respectively. Viscosity was measured by HAAKE Rotary Viscometer using spindle 5 at a rotation speed of $105 \mathrm{rpm}$. Iodine value test was performed to determine the amount of unsaturated groups present in each synthesized poly(silyl ether) according to Lubrizol Standard AATM 112-01. Thermal stability investigations were carried out using a Perkin Elmer TGA-6 under an inert $\mathrm{N}_{2}$ atmosphere at a heating rate of $10{ }^{\circ} \mathrm{C} / \mathrm{min}$. Then, $10 \mathrm{mg}$ of dried sample were loaded inside the alumina crucible, and the weight changes were monitored from $30-800{ }^{\circ} \mathrm{C}$. Differential Scanning Calorimetry (DSC) studies were carried out with a Perkin-Elmer Pyris Series 7 thermal analyzer at a heating rate of $10^{\circ} \mathrm{C} /$ min under an inert $\mathrm{N}_{2}$ atmosphere ranging from room temperature to $300^{\circ} \mathrm{C}$.

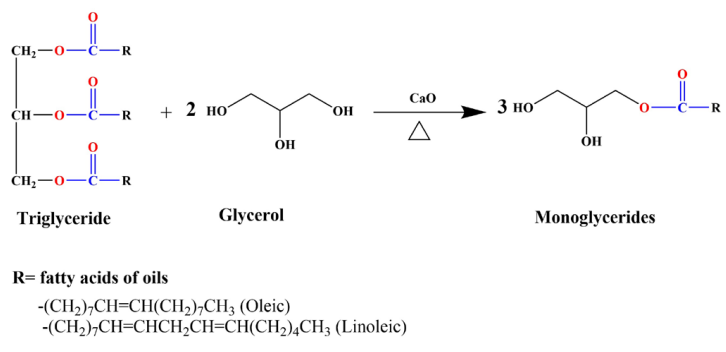

Scheme 1. Synthetic route of the monoglycerides.
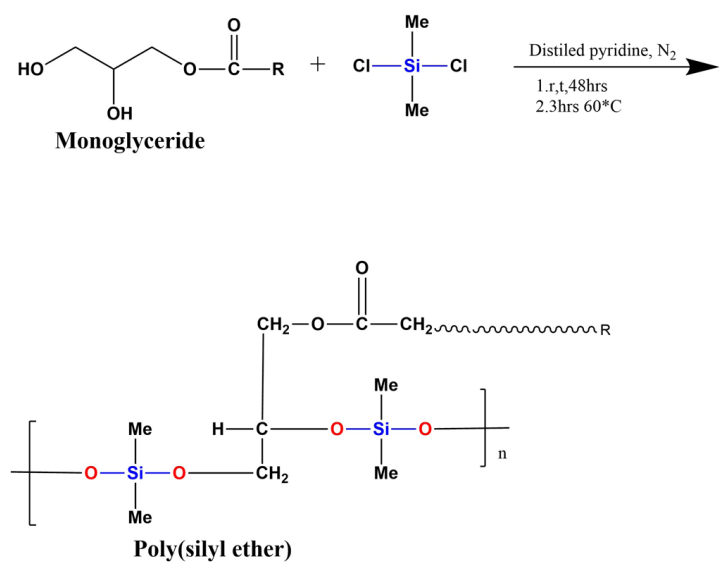

Scheme 2. Synthesis of the poly(silyl ether)s. 

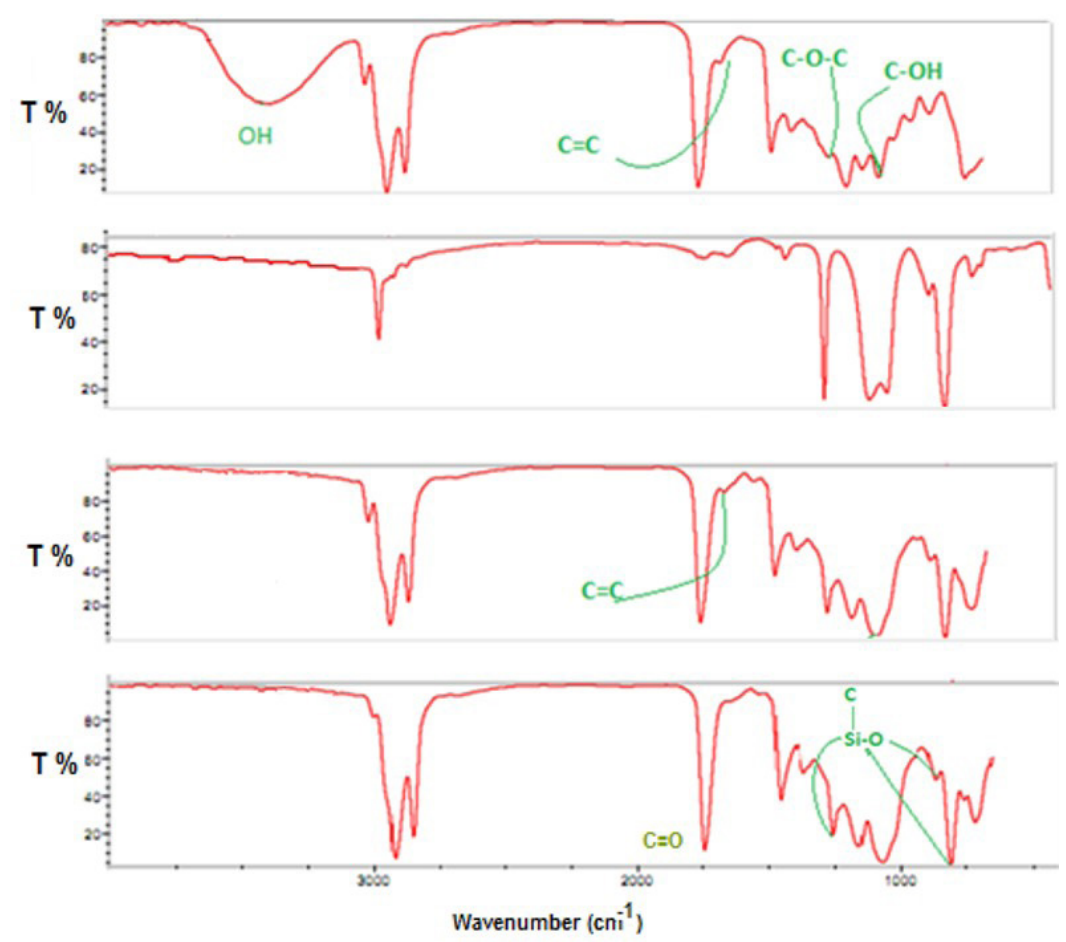

Figure 1. FT-IR spectra for monoglyceride, dichlorodimethylsilane, poly(silyl ether)s based palm oil and soy oil.

\section{Results and Discussion}

\subsection{Characterization of monoglycerides}

FT-IR spectra executed in the monoglycerides, dichlorodimethylsilane and poly(silyl ether)s are shown in Figure 1. For the oil monoglycerides, broad peak is observed at $3370.95 \mathrm{~cm}^{-1}$ which attributed to presence of the hydroxyl groups. A small peak appeared at $3090 \mathrm{~cm}^{-1}$ which may be due to $\mathrm{CH}=\mathrm{CH}$, whereas a sharp peak at $2922.93 \mathrm{~cm}^{-1}$ indicates the stretching of aliphatic C-H. Strong peak at $1737.21 \mathrm{~cm}^{-1}$ is attributed to the stretching of carbonyl $\mathrm{C}=\mathrm{O}$ group. A characteristic Si-O peak appears in the IR spectrum of poly(silyl ether)s at around 1050-1080 which represents the presence of Si-O linkages in the synthesized polymers. In addition, other absorption peaks appeared at $1653.70 \mathrm{~cm}^{-1} ; 1239.62 \mathrm{~cm}^{-1}$ and $1047.14 \mathrm{~cm}^{-1}$ are assigned for the presence of $\mathrm{C}=\mathrm{C}, \mathrm{C}-\mathrm{O}-\mathrm{C}$ bond and $\mathrm{C}-\mathrm{C}$, respectively.

The structures of monoglycerides (soy and palm) is further confirmed by ${ }^{1} \mathrm{H}$ NMR analysis and the type of protons, and their splitting are illustrated in Figures 2 and 3, respectively. The peaks for both the monoglycerides (palm and soy) are almost similar but only differ at the position $2.7 \mathrm{ppm}$ for palm based monoglyceride and at $2.8 \mathrm{ppm}$ for soy based monoglyceride. The spectra analysis confirmed the formation of polyols.

\subsection{Characterization of poly(silyl ether)s}

The structural elucidations of the polymers are confirmed by spectroscopic analyses such as FT-IR, ${ }^{1} \mathrm{H}$ and ${ }^{29} \mathrm{Si}$ NMR. The FT-IR spectra of the polymers in Figure 1 showed the

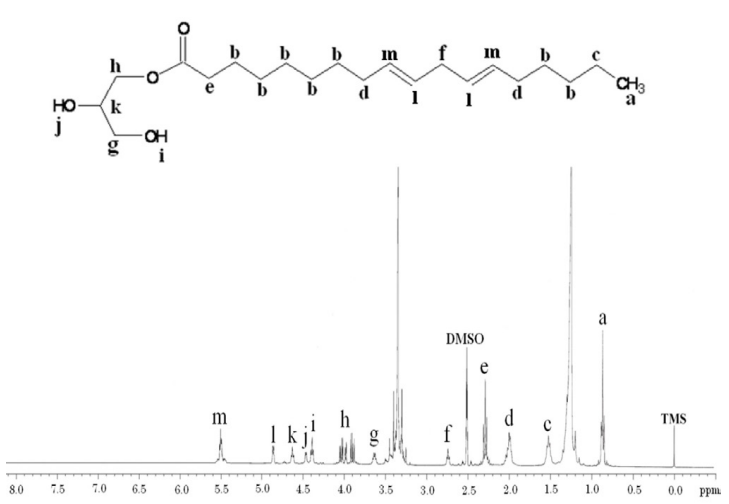

Figure 2. ${ }^{1} \mathrm{H}$ NMR of soya oil monoglyceride.

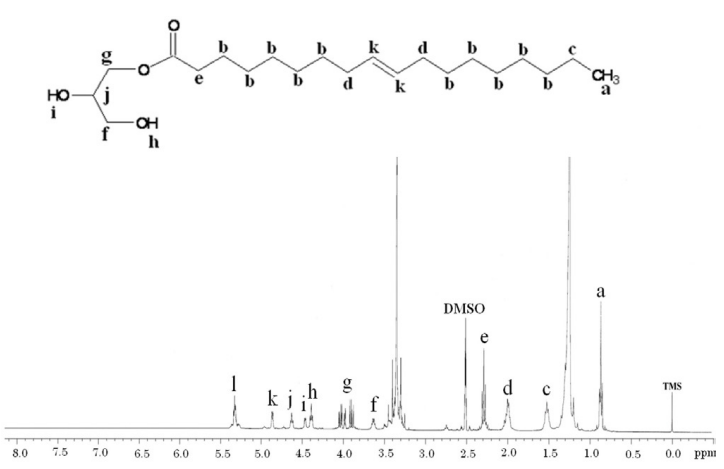

Figure 3. ${ }^{1} \mathrm{H}$ NMR of palm oil monoglyceride. 
appearance of new absorption bands at $1260 \mathrm{~cm}^{-1}$ and at $864 \mathrm{~cm}^{-1}$ which can be attributed to the $\mathrm{O}-\mathrm{Si}-\mathrm{CH}_{3}$. The disappearance of the absorption band at $3379 \mathrm{~cm}^{-1}$ for $-\mathrm{OH}$ group and the appearance of new peaks prove the completion of reaction and confirms the presence of $\mathrm{O}-\mathrm{Si}-\mathrm{O}$ in the backbone of the polymers. $\mathrm{C}=\mathrm{O}$ group is easily recognized by a strong, sharp band at $1737 \mathrm{~cm}^{-1}$. Weak peaks at $3090 \mathrm{~cm}^{-1}$ and at $1653 \mathrm{~cm}^{-1}$ are assigned to $\mathrm{CH}=\mathrm{CH}$ and $\mathrm{C}=\mathrm{C}$, respectively.

The ${ }^{1} \mathrm{H}$ NMR for poly(silyl ether)s based on monoglycerides of palm oil, and soy oil are shown in Figures 4 and 5, respectively. The spectra are obtained with deuterochloroform $\left(\mathrm{CDCl}_{3}\right)$ and without using tetramethylsilane (TMS) as the internal reference to avoid the overlap with protons of dimethylsilane based polymers. The ${ }^{1} \mathrm{H}$ NMR spectrum in Figure. 4 showed a new peak appearing at $0.2 \mathrm{ppm}$, which is attributed to the dimethylsilyl $\left(\mathrm{CH}_{3}\right)_{2}-\mathrm{Si}$. The prominent triplet peak at $0.8 \mathrm{ppm}$ is assigned to the proton at the terminal of a methyl group of fatty acid chains. Multiplet peaks at $1.2 \mathrm{ppm}$ are due to the protons in methylene groups $\left(-\mathrm{CH}_{2}\right)$. Proton attached to the carbonyl group $\left(\mathrm{CH}_{2}-\mathrm{CO}\right)$ centered at $2.35 \mathrm{ppm}$, whereas the proton of the vinylic groups $(\mathrm{C}=\mathrm{C}-\mathrm{H})$ appeared at $5.35 \mathrm{ppm}$. Protons of $\mathrm{CH}-\mathrm{O}$, $\mathrm{CH}_{2}-\mathrm{O}$ and $\mathrm{CH}_{2}-\mathrm{O}-\mathrm{CO}$ appeared at $4.15 \mathrm{ppm}, 3.7 \mathrm{ppm}$ and 4.16 ppm, respectively.

For the polymer based on monoglyceride of soy oil, it has a peak obvious at $2.75 \mathrm{ppm}$ which cannot be seen on the spectrum of the palm oil based polymer (Figure 5). This indicates that soy oil-based polymer has two double bonds, which give a clearer peak compared to palm oil, which has a smaller peak at the same position that indicates the presence of one double bond. It is well known that the linoleic in soy oil is responsible for the two double bonds while the oleic is responsible for one double bond for palm oil based polymer.

Furthermore, chemical structure of polymers is confirmed by ${ }^{29} \mathrm{Si}$ NMR. As evident from Figures 6 and 7, there are several peaks in the range of $-15 \mathrm{ppm}$ to $-25 \mathrm{ppm}$ which proved the presence of a silicon element in both poly(silyl ether)s. The corresponding chemical shifts characterize types of the silicon bonding, for example, peaks at -19.08 and $-19.11 \mathrm{ppm}$ are due to $\mathrm{CH}-\mathrm{O}-\mathrm{Si}$ for the polymers based on soy and palm oils, respectively. Other peaks at -21.53 and -21.88 ppm are assigned to $\mathrm{CH}_{2}-\mathrm{O}-\mathrm{Si}$ for the polymers based on soy and palm oils, respectively. Whereas, the silicon in $\mathrm{CH}_{3}-\mathrm{Si}_{-} \mathrm{CH}_{3}$ for the polymers based on soy and palm oils are centered at -22.02 and $-22.21 \mathrm{ppm}$, respectively. From the spectroscopic analyses, we can confirm the successful synthesis of poly(silyl ether)s.

\subsection{Properties of poly(silyl ether)s}

The viscosity of the poly(silyl ether) based on soy oil and palm oil were found to be $1137.8 \mathrm{cP} 1140.7 \mathrm{cP}$ at rotation of $105 \mathrm{rpm}$. The resistance of the flow for both the obtained polymers does not show much difference comparatively. As well, the viscosity for both of monoglycerides, palm and soy oils is measured, and found to be respectively, $110.2 \mathrm{cP}$ and $102.5 \mathrm{cP}$. It can be observed that the viscosity of the polymers is approximately 10 times then the viscosity of the monoglycerides which indicates the enormous increase in the molecular weights of the polymers, hereby signifying

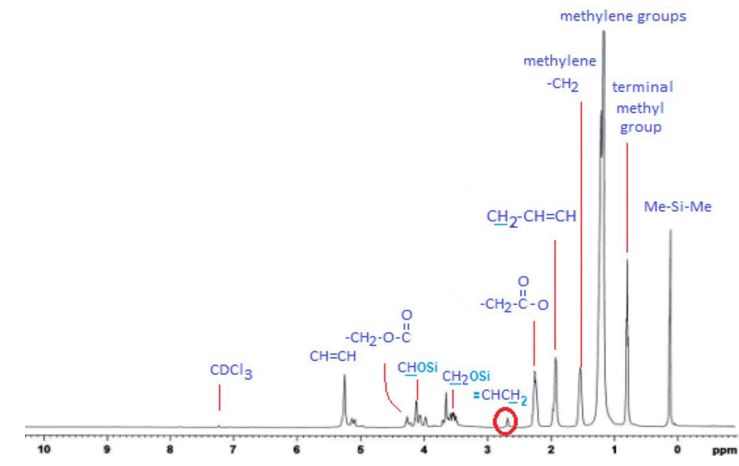

Figure 4. ${ }^{1} \mathrm{H}$ NMR spectra of poly(silyl ethers) based palm oil.

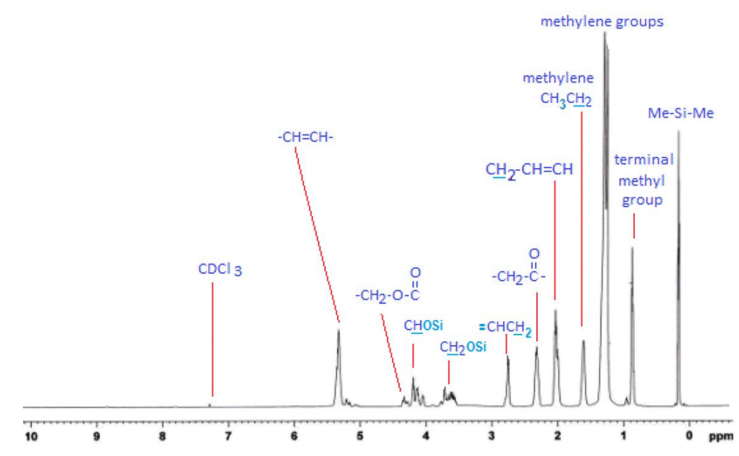

Figure 5. ${ }^{1} \mathrm{H}$ NMR spectra of poly(silyl ether)s based soy oil.

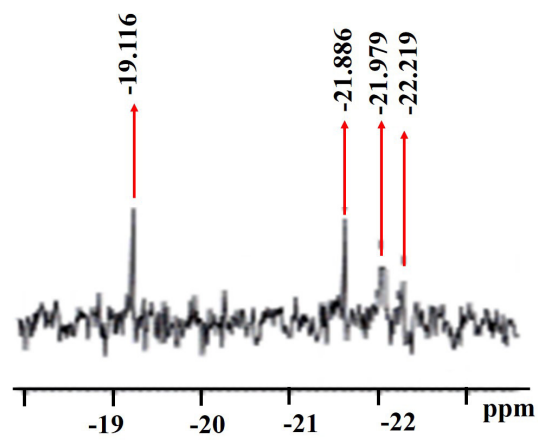

Figure 6. ${ }^{29} \mathrm{Si} \mathrm{NMR}$ of poly(silyl ether) derived from palm oil.

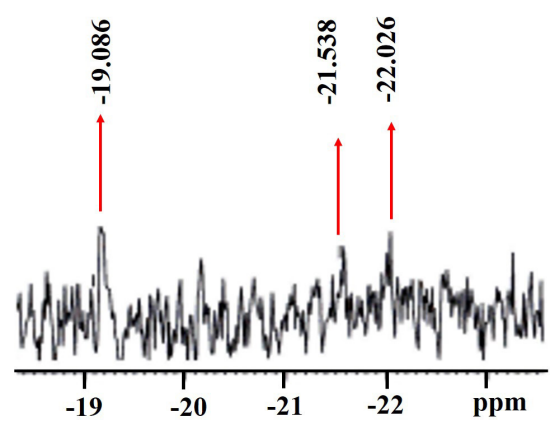

Figure 7. ${ }^{29} \mathrm{Si}$ NMR of poly(silyl ether) derived from soy oil. 
the efficacious synthesis of polymers. Thus, the higher the amount of cross linking, higher will be the formation of branched polymeric chains that led to additional binding effect and therefore enhances viscosity.

The iodine values analysis for poly(silyl ether)s is carried out by the procedure as described elsewhere ${ }^{29}$. The results exhibited the degree of unsaturation in these polymers based on palm and soy oils is found to be 55.56 and 120.5, respectively. Based upon the Iodine test it can be inferred that soy oil derived polymer has more unsaturated bonds as compared to the palm oil derived polymer since the number of double bonds found in soy oil are more than the palm oil. This is due to the fact that soy oil consists of higher constituent of linoleic acid, which has two double bonds in its structure as compared to the palm oil. Therefore, the higher iodine value denotes the higher double bond content in the polymer composition.

The thermal analysis of poly(silyl ether)s based on palm oil and soy oil, was carried out using thermogravimetric analysis performed under a nitrogen atmosphere by heating samples from $35-800{ }^{\circ} \mathrm{C}$ with a ramp rate of $10{ }^{\circ} \mathrm{C} / \mathrm{min}$. Figure 8 shows the TGA thermogram of the poly(silyl ether)s based on palm oil and soy oil. As is obvious from the TGA, the poly(silyl ether) based on soy oil, which is denoted the blue line, whereas poly(silyl ether) based on palm oil denoted by the red line undergoes two step degradation. As apparent from the TGA data, the thermal stability of these polymers is rather low and they began to degrade at a temperature below $250^{\circ} \mathrm{C}$. The low thermal stability of poly(silyl ether)s based on vegetable oils is due to the presence of long chain alkyl groups present in the main chain. Therefore, the initial degradation essentially starts from the long alkyl chain, and the second stage of degradation occurred due to the cleavage of Si-O linkage in the polymeric backbone.

It is evident from the Figure 8 and Table 1 that poly(silyl ether) based on soy oil at $T_{10}$ is more stable than poly(silyl ether) based on palm oil. This observation can

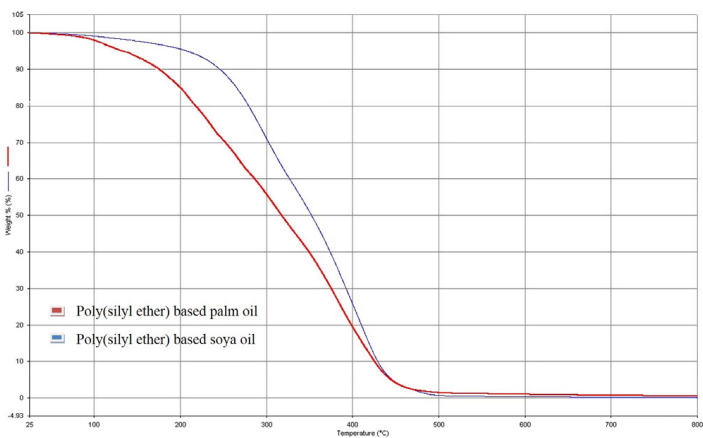

Figure 8. TGA curves of poly(silyl ether)s. be explained on the basis of the structure of soy oil based monoglyceride which possesses more double bonds, resulting strong intermolecular interactions, as compared to the poly(silyl ether) based on palm oil where the number of double bond is less in quantity. Similar observations have been reported on synthesis of polyurethanes based on soy and palm oils ${ }^{[23]}$.

To study the thermal behavior and phase transitions of the synthesized polymers DSC analysis were carried out using Perkin-Elmer Pyris Series 7 thermal analyzer at a heating rate of $10^{\circ} \mathrm{C} / \mathrm{min}$ under an inert $\mathrm{N}_{2}$ atmosphere ranging from room temperature to $300^{\circ} \mathrm{C}$. As apparent from Figure 9, Poly(silyl ether)s based on palm oil and soy oil exhibited endothermic peaks at $176^{\circ} \mathrm{C}$ and $82.9^{\circ} \mathrm{C}$ and the glass transition temperatures was found to be $31.6{ }^{\circ} \mathrm{C}$ and $34.2^{\circ} \mathrm{C}$, respectively. The glass transition occurred due to the increase in the heat capacity $\left(\mathrm{C}_{\mathrm{p}}\right)$ of the sample during heating, which is due to an enhancement in molecular motion of the polymeric chains ${ }^{[29]}$. It is suggested that the glass transition might be attributed to the long alkyl carboxyl groups present in the polymeric chain ${ }^{[23]}$. The DSC data again reveals that soy oil based poly(silyl ether) polymer is more thermally stable as compared with the palm oil based poly(silyl ether) polymer.

\subsection{Antibacterial activity}

Antimicrobial test is usually carried to determine antimicrobial potential of the polymers and to know which microbe's activity is hampered by presence of polymer. The standard used for these antimicrobial studies is Streptomycin with the concentration of $100 \mathrm{mg} / \mathrm{ml}$. The test is performed by placing $6 \mathrm{~mm}$ diameter of paper disc containing antibiotic and $6 \mathrm{~mm}$ diameter discs of polymer prepared by pressing the polymer using standard equipment onto the cultural agar plate with different strains of microbes. The microbe culture is standardized to $0.5 \mathrm{McF}$ arland standard which is

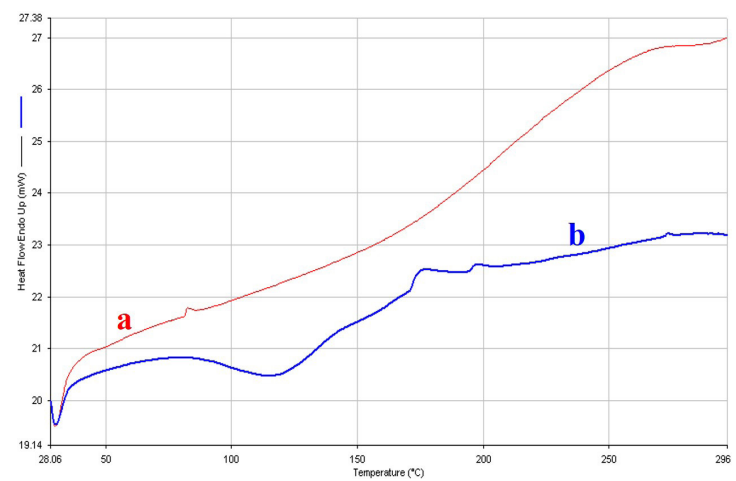

Figure 9. DSC curves of poly(silyl ether)s based on (a) Soy Oil and (b) Palm Oil.

Table 1. Thermal decomposition temperature of poly(silyl ether)s

\begin{tabular}{cccc}
\hline \multirow{2}{*}{ Poly(silyl ether)s } & Thermal decomposition temperature & Residue yield \\
\cline { 2 - 4 } & $\mathbf{1 0} \mathbf{w t} \%$ loss & $\mathbf{2 0} \mathbf{w t} \%$ loss & at 700 ${ }^{\circ} \mathbf{C ~}(\mathbf{\%})$ \\
\hline Palm Oil & 192 & 215 & 12 \\
Soya Oil & 256 & 290 & 10 \\
\hline
\end{tabular}


Table 2. Antibacterial activity of poly(silyl ether)s.

\begin{tabular}{lccc}
\hline \multirow{2}{*}{ Poly(silyl ether)s } & E. coli E266 & $\begin{array}{c}\text { Staphylococcus } \\
\text { aureus S276 }\end{array}$ & $\begin{array}{c}\text { Salmonella } \\
\text { choleraesuis } \\
\text { 10708 }\end{array}$ \\
\cline { 2 - 4 } & \multicolumn{2}{c}{ Diameter of Inhibition zones (mm) } \\
\hline Palm Oil & - & - & - \\
Soya Oil & 4 & - & 5 \\
Standard & 24 & 15 & 34 \\
\hline
\end{tabular}

approximately equals to $10^{8}$ cells per culture. Not more than 6 discs were placed on the same agar plate. Streptomycin is used as standard antibiotic for each bacterium. The plates were inverted and incubated at $30-37{ }^{\circ} \mathrm{C}$ for $16-24 \mathrm{hrs}$ or until sufficient growth has occurred and after incubation, each plate is examined for antimicrobial activity. The diameters of the zones of complete inhibition (as judged by the unaided eye) are measured, including the diameter of the disc. Zones are measured to the nearest whole millimeter, using sliding calipers or a ruler, which is held at the back of the inverted petri plate.

Antibacterial activity were studied against three different bacteria and the results showed that the poly(silyl ether) based on soy oil exhibits poor resistance, whereas the poly(silyl ether) based on palm oil didn't show any bioactivity. The results of the antibacterial are presented in Table 2.

\section{Conclusion}

Recently, vegetable oils have become one of the most important natural resources to synthesize polyol in order to replace the polyol based on petroleum sources. In summary, we present here a facile and distinctive route to synthesize the novel poly(silyl ether)s based on vegetable oils. The FT-IR, NMR and ${ }^{29} \mathrm{Si}$ NMR spectroscopy studies confirmed the successful formation of novel poly(silyl ether)s polyols. The low iodine value of monoglyceride based on palm oil indicates the higher saturation bond as compared to the monoglyceride of soy oil. From the viscosity data it was inferred that poly(silyl ether) based on palm oil possesses a higher viscosity as compared to the poly(silyl ether) based on soy oil. However, the thermal behavior showed lower stability than the poly(silyl ether) based on soy oil. Antibacterial activity has been screened against different bacteria and showed that poly(silyl ether)s possesses very poor resistance as compared to the standard drug that used in this study.

\section{Acknowledgements}

The authors would like to thank the University of Malaya (UM) and Sunway University for the research facilities and financial support through internal grant (INT-2018-SST-RCNMET-04).

\section{References}

1. Shahabuddin, S., Sarih, N. M., Mohamad, S., \& Atika Baharin, S. N. (2016). Synthesis and characterization of Co $3 \mathrm{O} 4$ nanocube-doped polyaniline nanocomposites with enhanced methyl orange adsorption from aqueous solution. RSC Advances, 6(49), 43388-43400. http://dx.doi.org/10.1039/C6RA04757B.

2. Shahabuddin, S., Muhamad Sarih, N., Mohamad, S., \& Joon Ching, J. (2016). SrtiO3 nanocube-doped polyaniline nanocomposites with enhanced photocatalytic degradation of methylene blue under visible light. Polymers, 8(27), 1-16. http://dx.doi.org/10.3390/polym8020027.

3. Stern, S., Shah, V., \& Hardy, B. (1987). Structure-permeability relationships in silicone polymers. Journal of Polymer Science. Part B, Polymer Physics, 25(6), 1263-1298. http://dx.doi. org/10.1002/polb.1987.090250607.

4. Nagaoka, K., Naruse, H., Shinohara, I., \& Watanabe, M. (1984). High ionic conductivity in poly (dimethyl siloxaneco-ethylene oxide) dissolving lithium perchlorate. Journal of Polymer Science. Part C, Polymer Letters, 22(12), 659-663. http://dx.doi.org/10.1002/pol.1984.130221205.

5. Dunnavant, W., Markle, R., Sinclair, R., Stickney, P., Curry, J., \& Byrd, J. (1968). p, p'-Biphenol-Dianilinosilane Condensation Copolymers. Macromolecules, 1(3), 249-254. http://dx.doi. org/10.1021/ma60003a010.

6. Dunnavant, W., Markle, R., Stickney, P., Curry, J., \& Byrd, J. (1967). Synthesis of polyaryloxysilanes by melt-polymerizing dianilino-and diphenoxysilanes with aromatic diols. Journal of Polymer Science. Part A, Polymer Chemistry, 5(4), 707-724. http://dx.doi.org/10.1002/pol.1967.150050402.

7. Curry, J. E., \& Byrd, J. D. (1965). Silane polymers of diols. Journal of Applied Polymer Science, 9(1), 295-311. http:// dx.doi.org/10.1002/app.1965.070090126.

8. Nagasaki, Y., Matsukura, F., Kato, M., Aoki, H., \& Tokuda, T. (1996). New thermosensitive rubbery polymers. Synthesis of poly (siloxyethylene glycol) and its aqueous solution properties. Macromolecules, 29(18), 5859-5863. http://dx.doi.org/10.1021/ ma9603721.

9. Nishikubo, T., Kameyama, A., Kimura, Y., \& Nakamura, T. (1996) New synthesis of poly (silyl ether) and poly (germyl ether) by addition reactions of bisepoxides with dimethyldiphenoxysilane and dimethyldiphenoxygermane. Macromolecules, 29(17), 5529-5534. http://dx.doi.org/10.1021/ma960304z.

10. Liaw, D.-J. (1997). Synthesis of poly (silyl ether) by the addition reaction of bisphenol-S diglycidyl ether and dichlorodiphenylsilane. Polymer, 38(20), 5217-5219. http:// dx.doi.org/10.1016/S0032-3861(97)00035-9.

11. Lan, X., Huang, W., \& Yu, Y. (2010). Synthesis, characterization and properties of the polysiloxane-based episulfide resin. European Polymer Journal, 46(7), 1545-1556. http://dx.doi. org/10.1016/j.eurpolymj.2010.04.011.

12. Jones, D. P., Carlson, J. L., Mody, V. C. Jr, Cai, J., Lynn, M. J., \& Sternberg, P. Jr (2000). Redox state of glutathione in human plasma. Free Radical Biology \& Medicine, 28(4), 625-635. http://dx.doi.org/10.1016/S0891-5849(99)00275-0. PMid:10719244.

13. Fernandes, R. A., Gholap, S. P., \& Mulay, S. V. (2014). A facile chemoselective deprotection of aryl silyl ethers using sodium hydride/DMF and in situ protection of phenol with various groups. RSC Advances, 4(32), 16438-16443. http:// dx.doi.org/10.1039/C4RA00842A.

14. Shahabuddin, S., Sarih, N. M., Ismail, F. H., Shahid, M. M., \& Huang, N. M. (2015). Synthesis of chitosan grafted-polyaniline/ Co $3 \mathrm{O} 4$ nanocube nanocomposites and their photocatalytic activity toward methylene blue dye degradation. RSC Advances, 5(102), 83857-83867. http://dx.doi.org/10.1039/C5RA11237K.

15. Baharin, S. N. A., Sarih, N. M., Mohamad, S., Shahabuddin, S., Sulaiman, K., \& Ma'amor, A. (2016). Removal of endocrine disruptor di-(2-ethylhexyl) phthalate by modified polythiophenecoated magnetic nanoparticles: characterization, adsorption 
isotherm, kinetic study, thermodynamics. RSC Advances, 6(50), 44655-44667. http://dx.doi.org/10.1039/C6RA04172H.

16. Mohammed, I., \& Lim, K. (2005). Synthesis and characterization of novel photoconducting polysiloxanes containing azomethine moieties. In The 230th ACS National Meeting (POLY 707). Washington: American Chemical Society - ACS.

17. Issam, A., \& Haris, M. (2009). Synthesis, characterization and optical properties of novel nonlinear polysilylether. Journal of Inorganic and Organometallic Polymers and Materials, 19(4), 454-458. http://dx.doi.org/10.1007/s10904-009-9301-9.

18. Nishikubo, T., Kameyama, A., Kimura, Y., \& Fukuyo, K. (1995). Novel Synthesis of Poly (silyl ethers) by the Addition Reaction of Bis (epoxides) with Dichlorosilanes or Bis (chlorosilanes). Macromolecules, 28(13), 4361-4365. http://dx.doi.org/10.1021/ ma00117a002.

19. Mosiewicki, M., Casado, U., Marcovich, N., \& Aranguren, M. (2009). Polyurethanes from tung oil: polymer characterization and composites. Polymer Engineering and Science, 49(4), 685-692. http://dx.doi.org/10.1002/pen.21300.

20. Tanaka, R., Hirose, S., \& Hatakeyama, H. (2008). Preparation and characterization of polyurethane foams using a palm oilbased polyol. Bioresource Technology, 99(9), 3810-3816. http:// dx.doi.org/10.1016/j.biortech.2007.07.007. PMid:17698355.

21. Issam, A., Khizrien, A. N., \& Mazlan, I. (2011). Physical and mechanical properties of different ratios of palm oil-based alkyd/ epoxy resins. Polymer-Plastics Technology and Engineering, 50(12), 1256-1261. http://dx.doi.org/10.1080/03602559.201 1.578289 .

22. Vashist, A., Shahabuddin, S., Gupta, Y., \& Ahmad, S. (2013). Polyol induced interpenetrating networks: chitosanmethylmethacrylate based biocompatible and $\mathrm{pH}$ responsive hydrogels for drug delivery system. Journal of Materials Chemistry. B, Materials for Biology and Medicine, 1(2), 168178. http://dx.doi.org/10.1039/C2TB00021K.
23. Mohammed, I. A., Al-Mulla, E. A. J., Kadar, N. K. A., \& Ibrahim, M. (2013). Structure-property studies of thermoplastic and thermosetting polyurethanes using palm and soya oils-based polyols. Journal of Oleo Science, 62(12), 1059-1072. http:// dx.doi.org/10.5650/jos.62.1059. PMid:24292358.

24. Guo, A., Zhang, W., \& Petrovic, Z. S. (2006). Structureproperty relationships in polyurethanes derived from soybean oil. Journal of Materials Science, 41(15), 4914-4920. http:// dx.doi.org/10.1007/s10853-006-0310-6.

25. Mohammed, I. A., Abd Khadir, N. K., \& Jaffar Al-Mulla, E. A. (2014). New polyurethane nanocomposites based on soya oil. Journal of Oleo Science, 63(2), 193-200. http://dx.doi. org/10.5650/jos.ess13099. PMid:24420063.

26. Saravari, O., Pathomwattanasak, K., \& Pimpan, V. (2007). Synthesis of urethane oils from palm oil and waste PET bottles. Journal of Applied Polymer Science, 105(4), 1802-1807. http:// dx.doi.org/10.1002/app.26185.

27. Caillol, S., Desroches, M., Boutevin, G., Loubat, C., Auvergne, R., \& Boutevin, B. (2012). Synthesis of new polyester polyols from epoxidized vegetable oils and biobased acids. European Journal of Lipid Science and Technology, 114(12), 1447-1459. http://dx.doi.org/10.1002/ejlt.201200199.

28. Liu, C., Yang, X., Cui, J., Zhou, Y., Hu, L., Zhang, M., \& Liu, H. (2011). Tung oil based monomer for thermosetting polymers: synthesis, characterization and copolymerization with styrene. Bioresources, 7(1), 447-463.

29. Ling, J. S., Mohammed, I. A., Ghazali, A., \& Khairuddean, M. (2014). Novel poly (alkyd-urethane) s from vegetable oils: Synthesis and properties. Industrial Crops and Products, 52, 74-84. http://dx.doi.org/10.1016/j.indcrop.2013.10.002.

Received: Oct. 20, 2017

Revised: Feb. 27, 2018

Accepted: Apr. 15, 2018 